\title{
Soil Moisture Retrieval Quantitatively with Remotely Sensed Data and Its Crucial Factors Analysis
}

\author{
Ji JIAN ${ }^{1,2 *}$, Peifen PAN ${ }^{1}$, Yuanyuan CHEN ${ }^{1}$, Wunian YANG ${ }^{1}$ \\ ${ }^{1}$ Institute of RS and GIS, Chengdu University of Technology, Chengdu, China \\ ${ }^{2}$ International Institute for Earth System Science, Nanjing University, Nanjing, China \\ E-mail: jianji@cdut.cn \\ Received September 10, 2009; revised October 9, 2009; accepted October 22, 2009
}

\begin{abstract}
The Ts/NDVI method was adopted to retrieve soil moisture with multi-temporal and multi-sensor remotely sensed data f ETM+ and ASTER in study area. The retrieved soil moisture maps were consistent with the soil type and vegetation, which were also the two main factors determining the distribution of soil moisture.
\end{abstract}

\section{Keywords: Soil Moisture, Quantitative Remote Sensing, NDVI}

\section{Introduction}

The Biospheric Aspects of the Hydrological Cycle (BA$\mathrm{HC}$ ), one of the core projects of the International Geosphere Biosphere Programme (IGBP) coordinated by the International Council for Science (ICSU), was established to study the role of vegetation in the hydrological interactions between the land surfaces and atmosphere. One objective of BAHC is to determine the biospheric controls of the hydrological cycle through field measurements for the purpose of developing models of energy and water fluxes in the soil-vegetation-atmosphere system at temporal and spatial scales ranging from vegetation patches to General Circulation Model (GCM) grid cells [1,2]. This encouraged us to focus not only on the water itself, but also on its correlation factors such as the vegetation, the ground and so on when studying water environments and water resources, especially for water closely related to vegetation [3-9]. Soil moisture observations are one of these studies. Soil moisture is a key component of the hydrological cycle, controlling the partitioning of precipitation between runoff, evapotranspiration and deep infiltration. As a link between the biosphere and the edaphic zone, soil water plays a crucial role in terrestrial ecosystems by determining plant growth. If the soil water level falls below a species-specific threshold, plants experience water stress, and decreased soil moisture under warmer conditions can inhibit photosynthesis [10]. Soil moisture observations over large areas are increasingly required in a range of environmental applications including meteorology, hydrology, water resource management and climatology. Remote sensing can provide considerable cost-and time-savings when applied to mapping soil moisture over large areas. Various approaches have been developed over the past two decades to infer near-surface soil moisture from remote sensing measurements of surface temperature, radar backscatter and microwave brightness temperature [11-15].

In this paper, the soil moisture in study area was retrieved with Landsat Enhance Thematic Mapper Plus (ETM+) data and Advanced Spaceborne Thermal Emission and Reflection Radiometer (ASTER) data first, then, the influence factors of soil moisture was analyzed. The objective of this paper is to provide a new method for soil moisture monitoring.

\section{Methods}

\subsection{Study Area}

In this paper, the Maoergai area (from latitude $32^{\circ} 20^{\prime}$ to $32^{\circ} 40^{\prime}$ north and from longitude $103^{\circ} 00^{\prime}$ to $103^{\circ} 30^{\prime}$ east, shown as Figure 1), located in the upper Minjiang river, northern Sichuan province, in the southwest of China, was selected as the study area. The upper Minjiang river area has been famous as a "natural barrier" and the "green lake" of Sichuan province for a long time, where the forest area reached 12 thousand $\mathrm{km}^{2}$, almost $50 \%$ of the whole 24.5 thousand $\mathrm{km}^{2}, 600$ years ago. However, with the destruction of the forest, it had been reduced to only 7.4 thousand $\mathrm{km}^{2}$, or about $30 \%$ of the whole area, by 1950 . Meanwhile, the upper Minjiang is transforming from a pristine region to one with an increasing level of human activity, which leads to a degraded ecosystem in the area. The study area is a specific area in the upper Minjiang River with regard to its vegetation, soil, and mountainous characters, thus, the study result can be popularized in Minjiang river basin. 


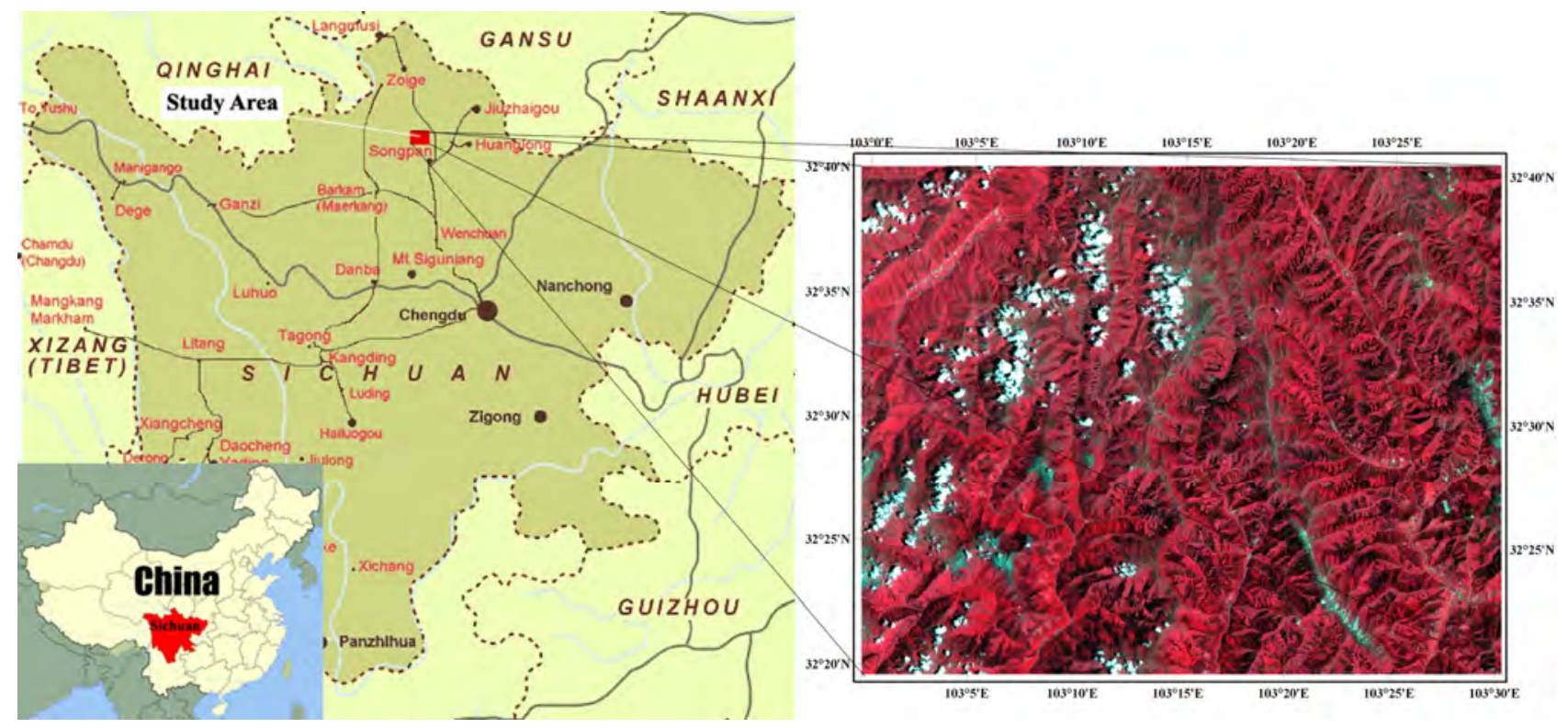

Figure 1. Location of the study area.

\subsection{Data}

In this study, we collected the soil type, groundwater and vegetation distribution data of the study area for the year 2000, which were collected within the gold-eye project subsidized by National High Technology Research and Development Program (HTRDP) [16], 48 ground control points (GCPs) distributed averagely in study area, the moisture of representative bare soils in the study area , the moisture of representative vegetations in the study area , all spectrums of representative soil and representative vegetation in the study area, Landsat ETM+ data of 10 July 2002 and ASTER data of 2 November 2003 of the study area for retrieving soil moisture. The remotely sensed data have been registered to UTM WGS-84 coordinates using the GCPs to allow co-registration of the ground data.

\subsection{Retrieval and Analysis Processes}

The retrieval and analysis processes were divided into 3 parts in this paper: First, pre-process of remotely sensed data, including geometric register, radiometric correction(radiometric calibration, topographic correction and atmospheric correction); Second, retrieval of biophysical parameter for land cover, including vegetation indices, soil brightness, soil wetness, greenness and surface temperature; Third, soil moisture retrieval with Ts/NDVI model and soil moisture analysis with soil type distribution data, vegetation distribution data and groundwater distribution data.

To better understand the soil moisture retrieval and analysis processes, a flow chart is provided in Figure 2.

\section{Results}

\subsection{Soil Moisture Retrieval from Landsat ETM+ Data}

Surface temperature ( $T_{s}$, Kelvin), normalized difference vegetation index (NDVI) and the feature special diagram retrieved from ETM+ data of July 2002 in study area were shown in Figure 3.

To calculate the relative soil moisture, the dry edge linear equation and wet edge linear equation of $T_{s} / N D V I$ feature space should be calculated first. The dry and wet edge linear equations are calculated as follows:

Dry edge:

$$
T_{\text {S-max }}=-18.356343 * N D V I+307.57766 \mathrm{r}=0.47030258
$$

Wet edge:

$$
T_{S-\min }=0.68168266 * N D V I+288.26377=0.30658477
$$

With the data of soil moisture and experiential formulas $[1,2,4,8-10]$ in study area as a reference, the relativesoil moisture of any point in ETM+ data's $T_{s} / N D V I$ feature space was calculated as Equation 3, where RSM is the relative soil moisture of any point, $T$ is the surface temperature of the point, $T_{D}$ is the surface temperature of dry edge which is corresponding to the $N D V I$ of the point and $T_{w}$ is the one of wet edge.

$$
R S M=100-\frac{T-T_{W}}{T_{D}-T_{W}} \times 59.29378862
$$

Then, with the Equation 3, the relative soil moisture of 


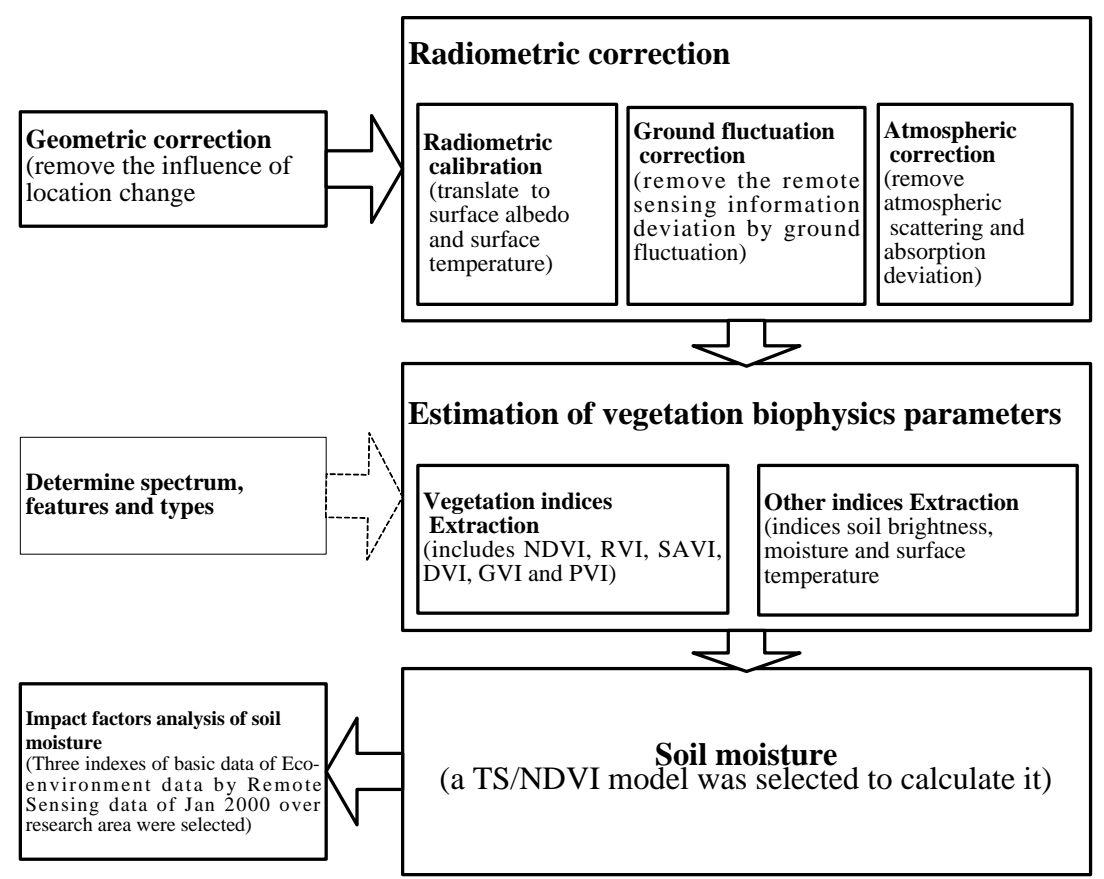

Figure 2. Flow chart of the soil moisture retrieval and analysis.

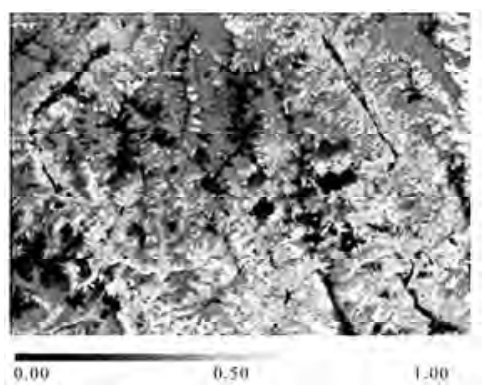

(a) NDVI

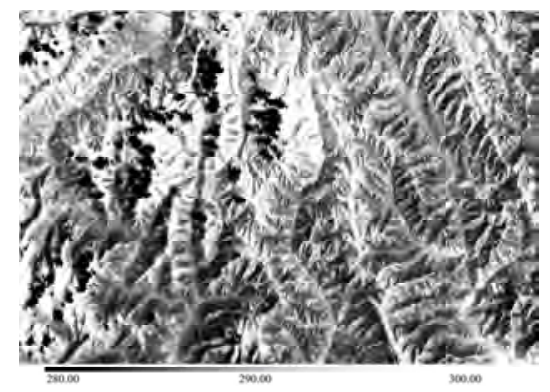

(b) Surface temperature(K)

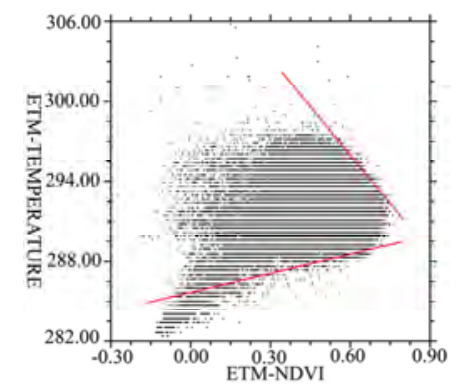

(c) TS-NDVI feature space

Figure 3. NDVI, surface temperature and feature space diagram retrieved from ETM+ data.

every pixel can be calculated. With the relative data of soil moisture content data and investigation data in study area as a reference, the practical soil moisture retrieved from ETM+ of July 2002 in study area is shown as Figure 4. According to Figure 4, the soil moisture was relatively high in July 2002 in study area; most points have a soil moisture between $18 \%$ and $25 \%$, while few points have a soil moisture less than $15 \%$. Contrasting the soil moisture map with the terrain and false colour maps, we can get that the soil moisture have a relatively high relation with the distribution of vegetation and terrain: the point near to water has a higher soil moisture value, vice versa; the point far from water has a relatively low soil moisture value.

\subsection{Soil Moisture Retrieval from ASTER Data}

The surface temperature ( $T_{S}$, Kelvin), the normalized difference vegetation index (NDVI) and the feature spe- cial diagram retrieved from ASTER data of November 2003 in study area were shown as Figure 5.

As the data process of ETM+ data above, the dry edge linear equation and wet edge linear equation in ASTER $T_{S} / N D V I$ feature space were calculated first, shown as Equations (4) and (5).

Dry edge:

$$
\begin{aligned}
T_{\text {S-max }} & =-35.698122 * N D V I+307.18527 \\
\mathrm{r} & =0.78242239
\end{aligned}
$$

Wet edge:

$$
\begin{aligned}
T_{S-\min } & =7.9501126 * \mathrm{NDVI}+271.93125 \\
\mathrm{r} & =0.64890765
\end{aligned}
$$

With the data of soil moisture and experiential Formulas [17] in study area being as a reference, the relative soil moisture of any point in ETM+ data's $T_{S} / N D V I$ feature space was calculated as Equation 6. Where RSM is the relative soil moisture of a point, $T$ is the surface temperature of the point, and $T_{D}$ is the surface temperature of 


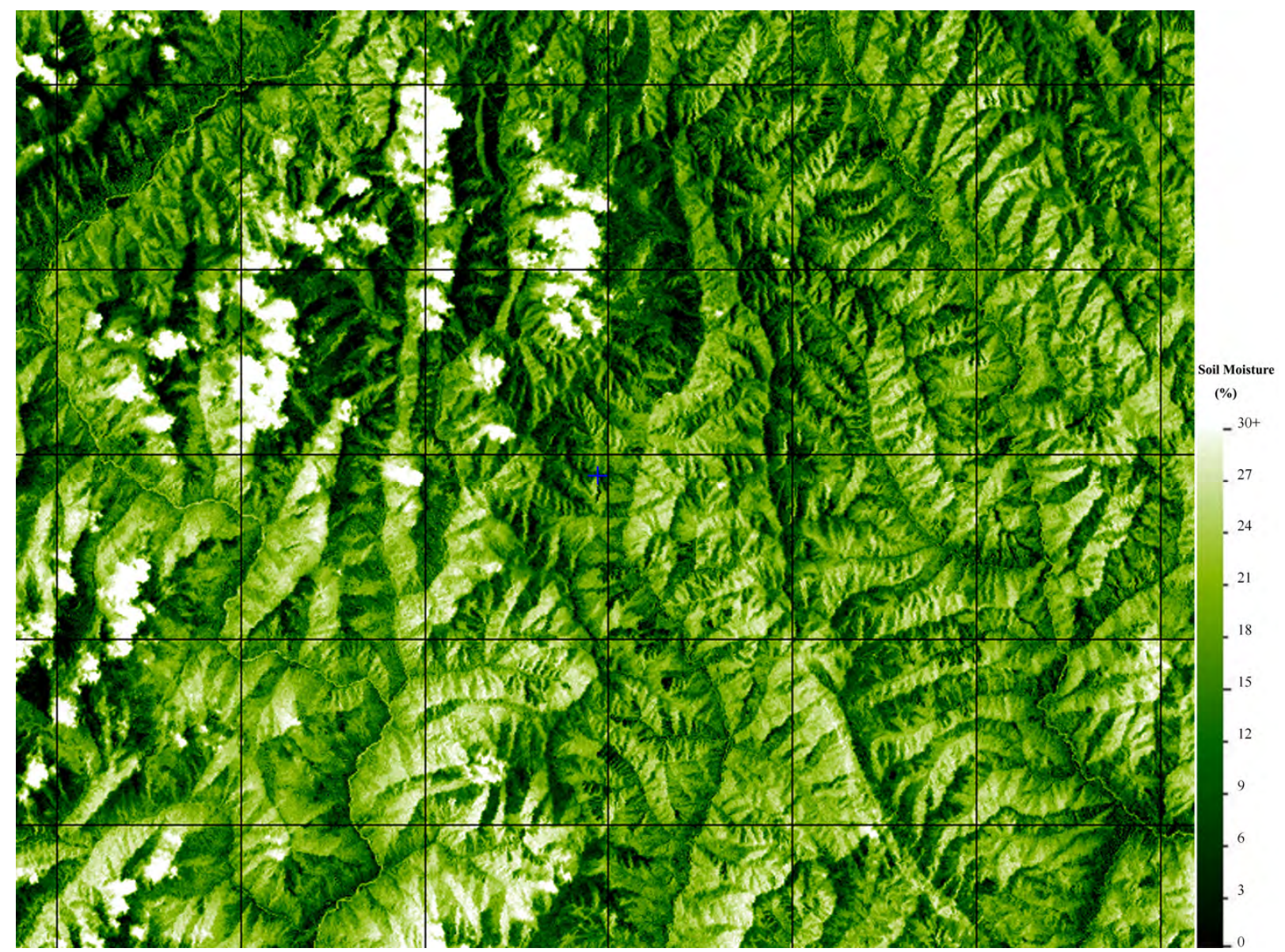

Figure 4. Overlaid map of groundwater distribution map with the soil moisture map retrieved from Remotely Sensed data. (White lines are the boundaries of groundwater, red words are groundwater codes).

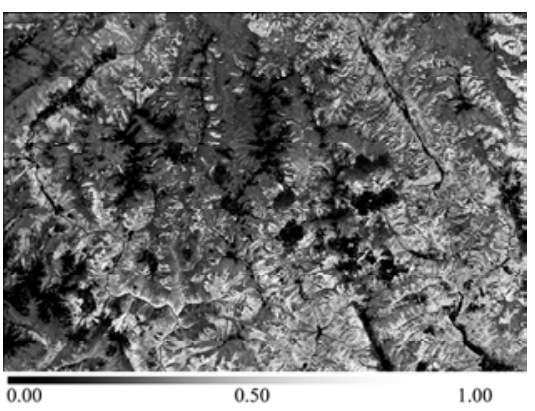

(a) NDVI

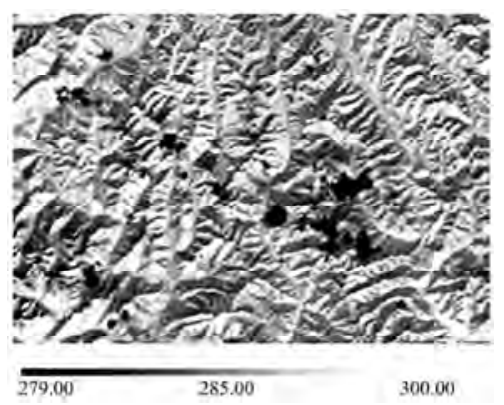

(b) Surface temperature(K)

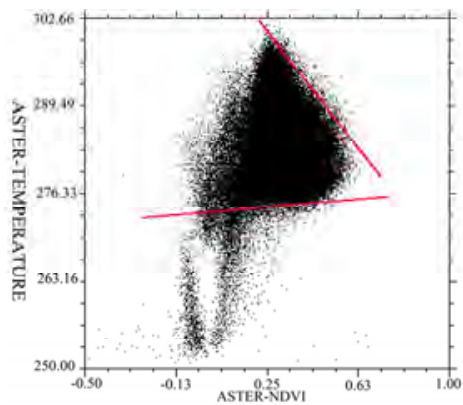

(c) TS-NDVI feature space

Figure 5. NDVI, surface temperature and feature special diagram retrieved from ASTER data.

dry edge.

$$
R S M=100-\frac{T-T_{W}}{T_{D}-T_{W}} \times 79.29378862
$$

Then, with the Equation 6, the relative soil moisture of every pixel can be calculated. With the relative data of soil moisture content data and investigation data in study area being as a reference, the practical soil moisture retrieved from ETM+ of July 2002 in study area was shown as Figure 6. According to Figure 6, the soil mois- ture was widely distributed in November 2003 in study area, between $5 \%$ and $25 \%$, the reason is mostly like that it was the time when autumn was changing into winter with some bare land and some evergreen woods, leading to a various kinds of soil moisture distribution but most between $10 \%$ and $20 \%$, which was consistent with practical situation. Some points have soil moisture of 0 , the reason is mostly like that the soil moisture of bare rock and hardened soil in this season was very low. Meanwhile, some points have relatively high soil moisture, the 


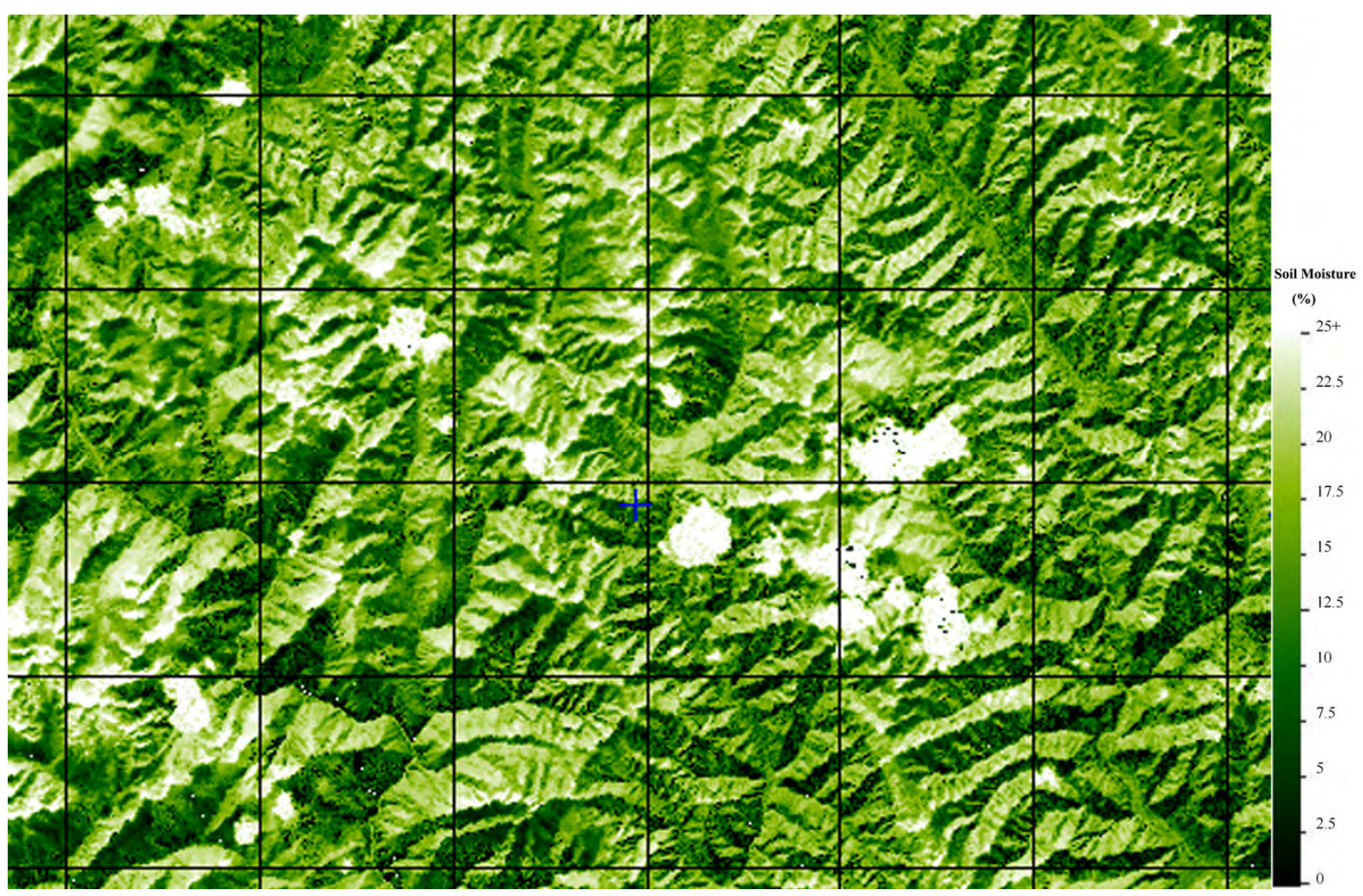

Figure 6. Soil moisture image by ASTER in research area (\%).

reason is mostly like that snow and clouds exist in ASTER data.

Contrasting Figure 4 with Figure 6, the soil moisture retrieved from ASTER data of November 2003 in study area has a relatively lower value than that retrieved from ETM+ of July 2002, the reason is that there is less water in winter but more in summer in study area.

\section{Discussion}

From the results above, we can see that soil moisture was closely related to soil type, vegetation type and water. In order to make clearer the relationship between soil moisture and soil type, vegetation type and water, the distribution map of soil moisture was overlaid on the distribution map of vegetation type, soil type and water system.

Figure 7 is the overlaid map of the soil type distribution map with the soil moisture distributed map retrieved from ETM+ and ASTER. From the contrast of Figure 7(a) and 7(b), we can see that soil moisture distributed map is deeply related to soil type, that is to say, soil moisture is different from one kind soil to another. As a whole, the soil moisture of brown soil (with code of B210) and dark brown soil (with code of B310) is higher, but the soil moisture of terra cinnamon soil' (with code of C212) is lower, the soil moisture of other soil types are mid. However, the soil moisture of the same soil is different with the place change, which is similar in the two maps. Also, the soil moistures of different soils in different seasons are different.

Figure 8 is the overlaid map of the groundwater distribution map with the soil moisture distributed map retrieved from ETM+ and ASTER. From the contrast of Figure 8(a) and 8(b), we can see that the distribution of groundwater has some effect on soil moisture distribution, but the influence is weaker than the soil types'. General speaking, the influence of groundwater on soil moisture is stronger in summer than it is in winter; the reason is that the evapotranspiration is stronger in summer.

Figure 9 is the overlaid map of the vegetation distribution map with the soil moisture distributed map retrieved from ETM+ and ASTER. From the contrast of Figure 9(a) and 9(b), we can see that the distribution of soil moisture map is highly related to vegetation. Soil moisture varied with vegetation change. General speaking, the soil moisture on evergreen forest land is relatively higher, while cutover land's is relatively lower. With the season change, the relativity of vegetation and soil moisture would change accordingly, because most deciduous forests' evapotranspiration is different in different seasons, lead- 


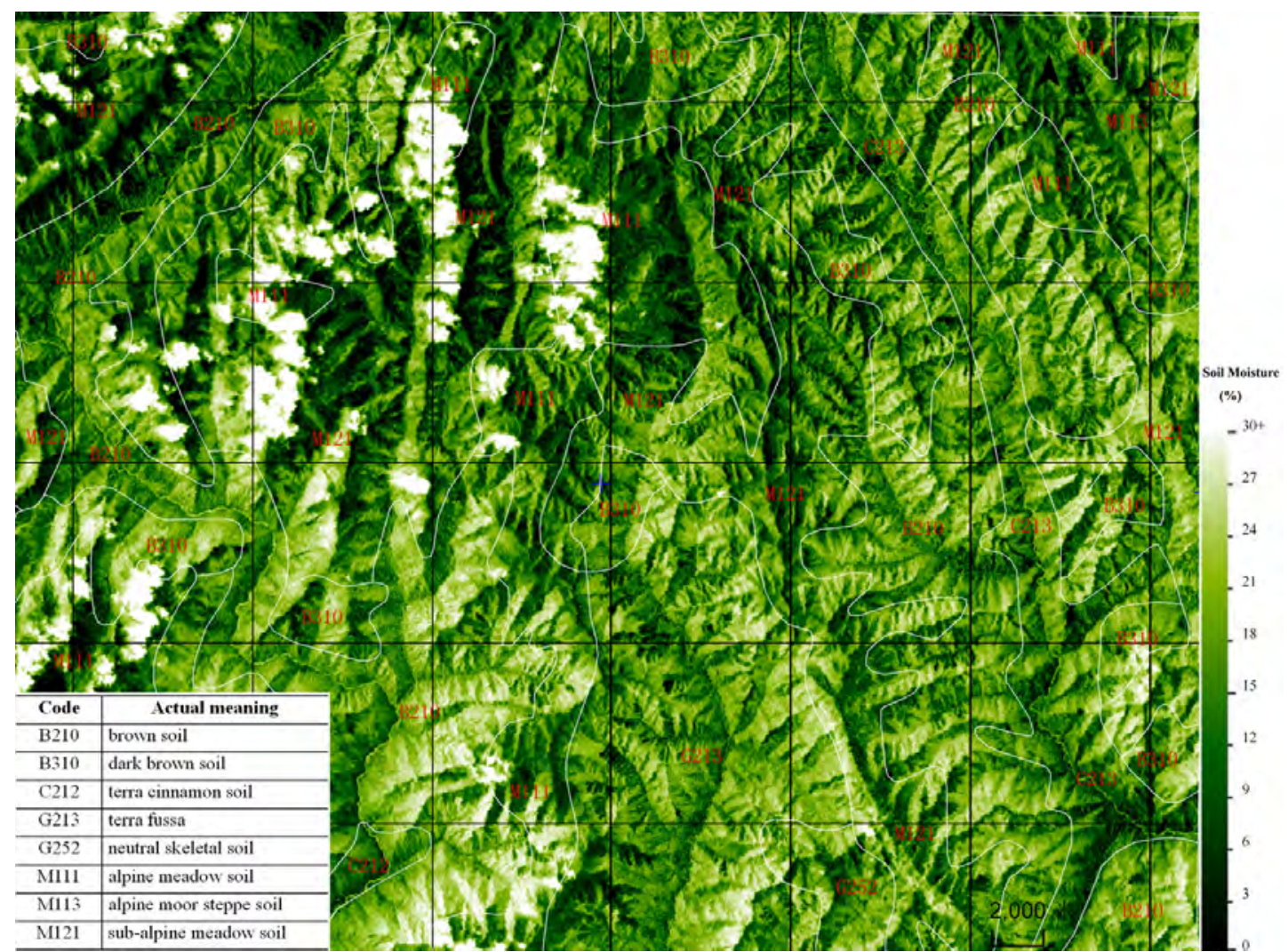

(a).Overlaid map of soil type distribution map with soil moisture map retrieved from ASTER.

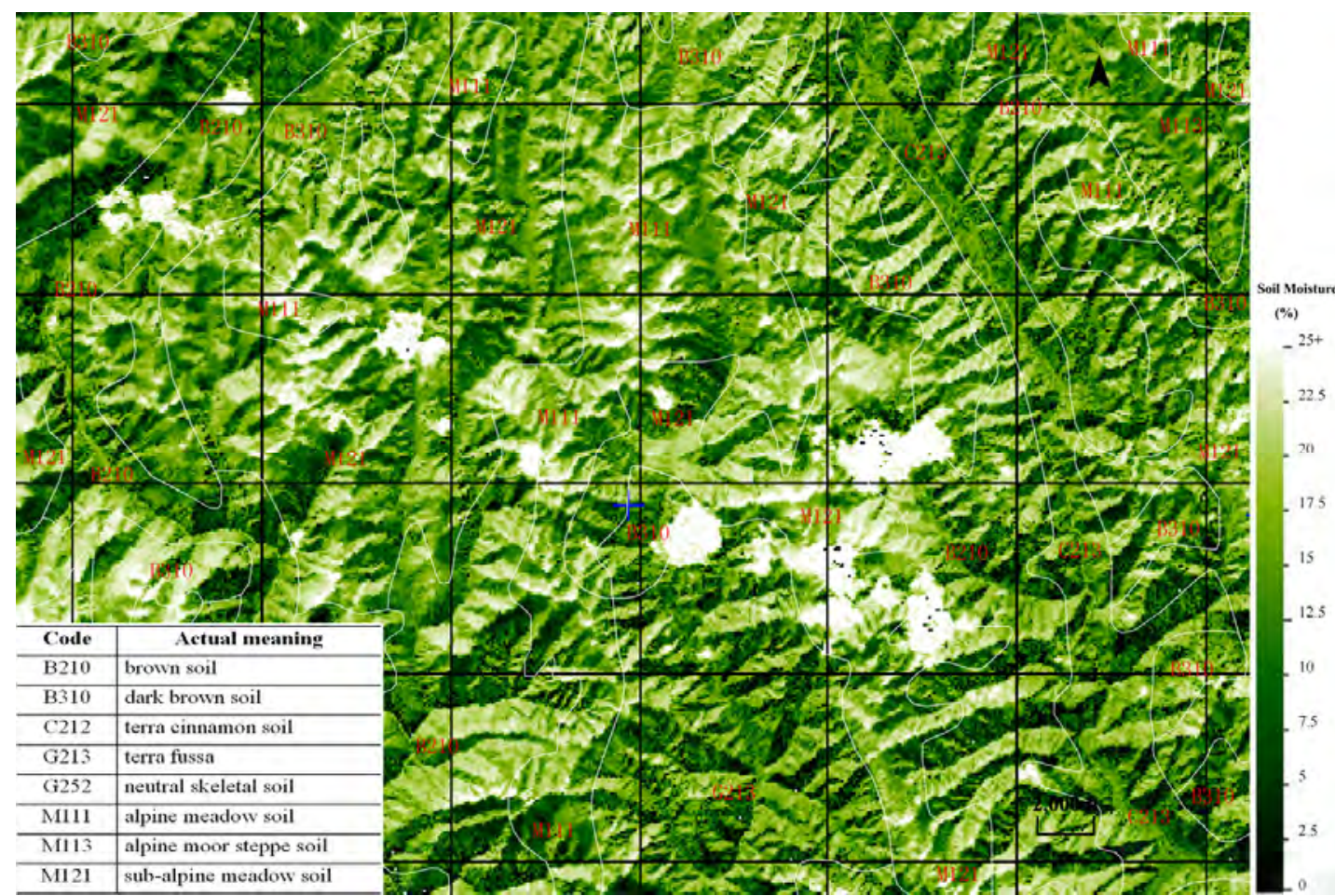

(b).Overlaid map of soil type distribution map with soil moisture map retrieved from ETM.

Figure 7. Overlaid map of the soil type distribution map with the soil moisture map retrieved from Remotely Sensed data. (White lines are the boundaries of soil types, red words are soil codes). 


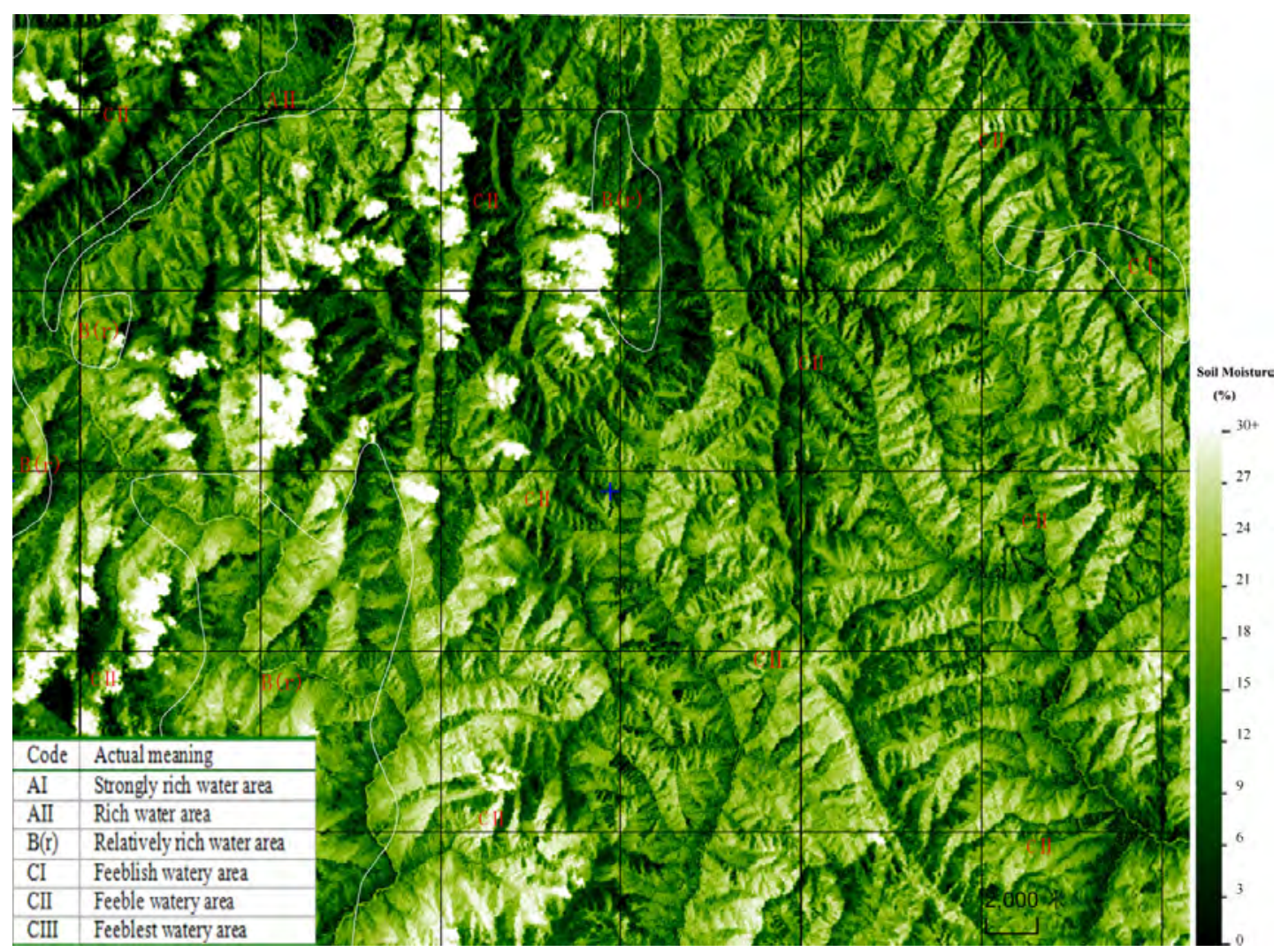

(a).Overlaid map of groundwater distribution map with soil moisture map retrieved from ETM.

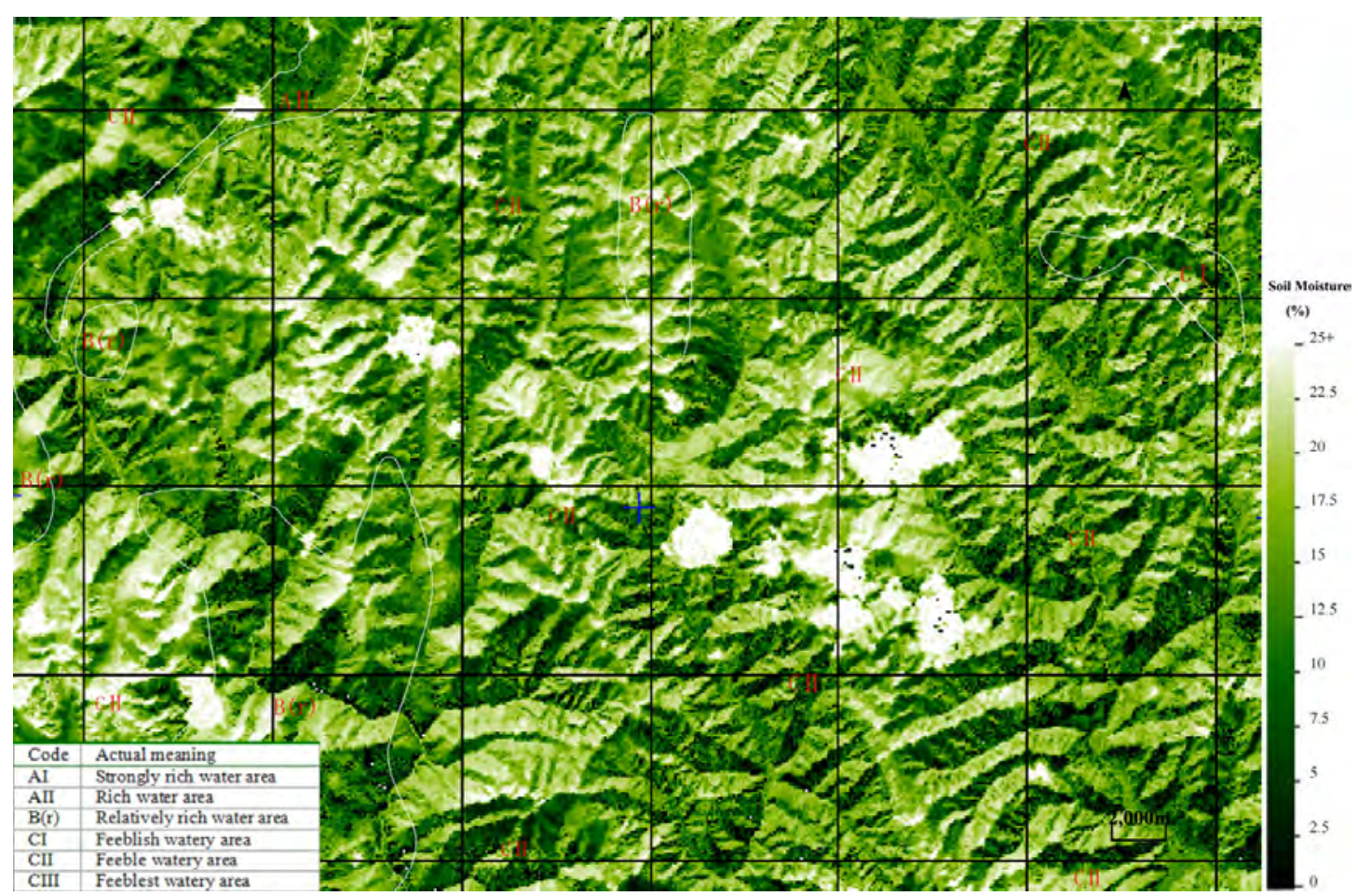

(b).Overlaid map of groundwater distribution map with soil moisture map retrieved from ASTER.

Figure 8. Overlaid map of groundwater distribution map with the soil moisture map retrieved from Remotely Sensed data. (White lines are the boundaries of groundwater, red words are groundwater codes). 


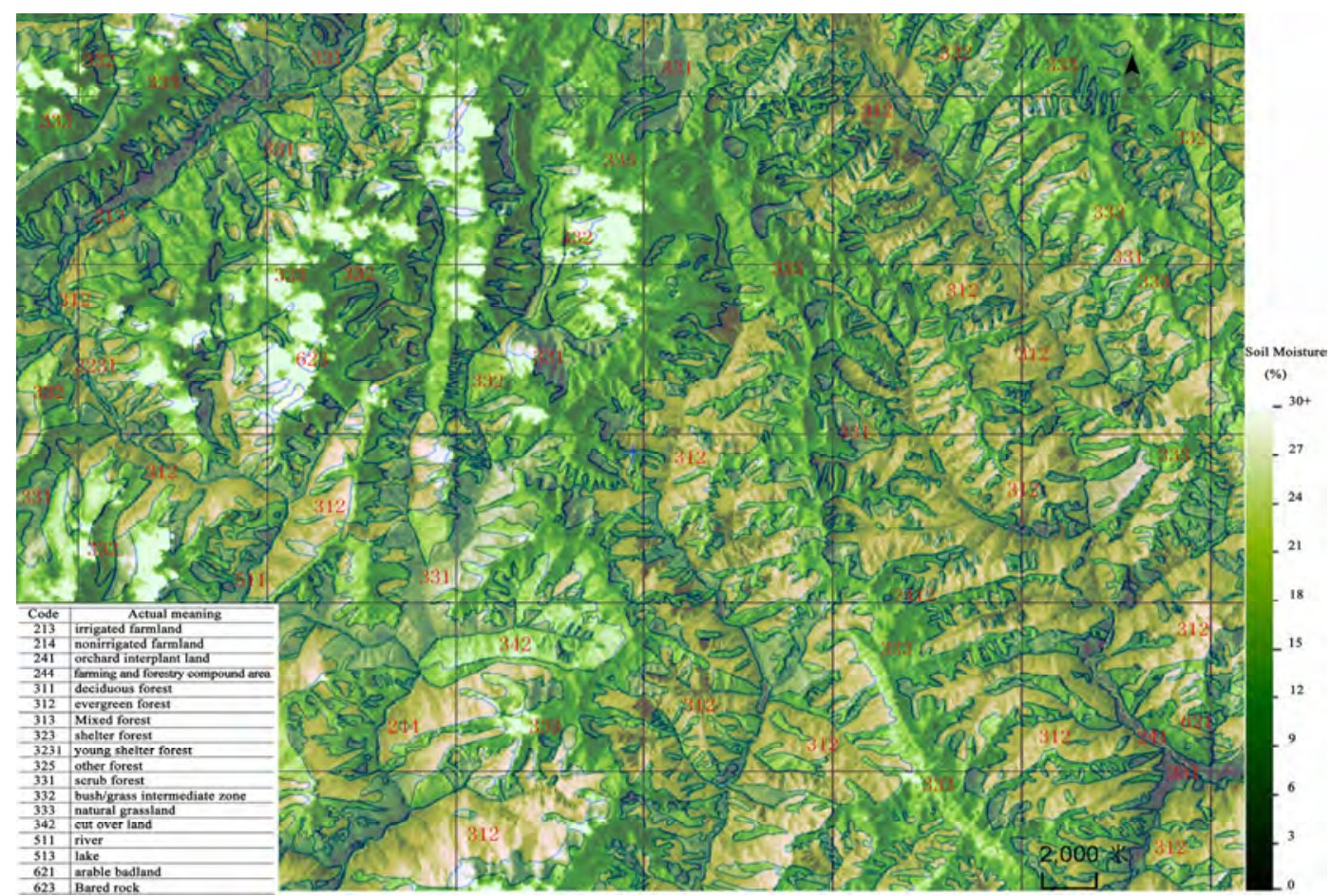

(a).Overlaid map of vegetation distribution map with soil moisture map retrieved from ETM.

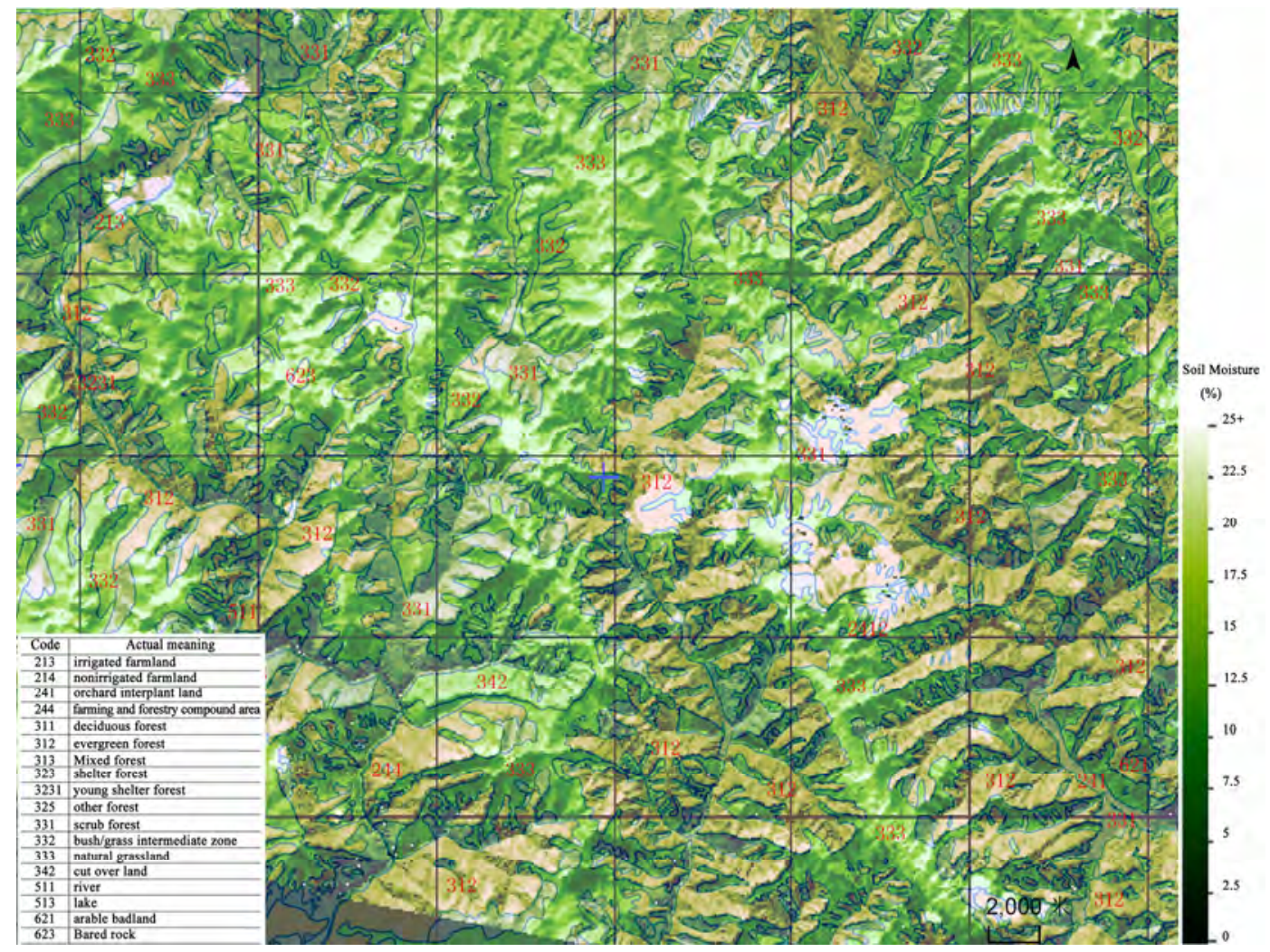

(b).Overlaid map of vegetation distribution map with soil moisture map retrieved from ASTER.

Figure 9. Overlaid map of vegetation distribution map with the soil moisture map retrieved from remotely sensed data. (Blue lines are the boundaries of groundwater, red words are groundwater codes). 
ing to the change of the ratio of soil water-holding.

From the analysis above, the model to retrieve soil moisture from remotely sensed data is viable, and, the potential influence factors of soil moisture are soil type and vegetation type.

\section{Conclusions}

In this paper, with the ETM+ and ASTER data, the soil moisture maps in study area were retrieved. The retrieved soil moisture maps were in agreement with the soil type and vegetation, which were also the two main factors determining the distribution of soil moisture.

As the remote sensing retrieval model of soil moisture was complex, the study was only at the beginning. In the following work, the authors plan to investigate soil moisture with hyper-spectral remotely sensed data to raise the accuracy and reliability of soil moisture retrieval.

\section{Acknowledgments}

The research was supported by the Science and Technology Bureau of Sichuan Province of China. The authors sincerely thank Hong Jiang, from Nanjing University, Li Peng, from Chengdu University of Technology for their suggestions and help.

\section{References}

[1] R. W. A. Hutjes, P. Kabat, et al., "Biospheric aspects of the hydrological cycle," Journal of Hydrology, Vol. 212-213, pp. 1-21, 1998.

[2] Y. Gao and C. Wang, "Biospheric aspects of hydrological cycle: BAHC plan and its research progress,” Progress in Geography, Vol. 19, pp. 97-103, 2000.

[3] D. Entekhabi, H. Nakamurai, and E. G. Njoku, "Solving the inverse problem for soil moisture and temperature profiles by sequential assimilation of multifrequeney remotely sensed observations," IEEE Transactions on Geoscience and Remote Sensing, Vol. 32, pp. 438-448, 1994.

[4] IGPB, WCRD and IHDP, “Abstract volume of challenge of a changing earth," in Proceedings Global Change Opening Science Conference, Amsterdam, Netherland, pp. 10-13, July, 2001.

[5] D. Gerten, S. Schaphoff, U. Haberlandt, W. Lucht, and S. Sitch, "Terrestrial vegetation and water balance-hydrological evaluation of a dynamic global vegetation mode,” Journal of Hydrology, Vol. 286, pp. 249-270, 2004.
[6] N. A. Brunsell, "Characterization of land-surface precipitation feedback regimes with remote sensing," Remote Sensing of Environment, Vol. 112, pp. 200-211, 2006.

[7] R. H. French, J. J. Miller, C. Dettling, and J. R. Carr, "Use of remotely sensed data to estimate the flow of water to a playa lake,” Journal of Hydrology, Vol. 325, pp. 67-81, 2006.

[8] M. S. Feldman, T. Howard, E. McDonald-Buller, G. Mullins, D. T. Allen, A. Webb, and Y. Kimura, "Applications of satellite remote sensing data for estimating dry deposition in eastern Texas,” Atmospheric Environment, Vol. 44, pp. 7562-7576, 2007.

[9] E. García-Cuesta, I. M. Galván, and A. J. de Castro, "Multilayer perceptron as inverse model in a groundbased remote sensing temperature retrieval problem," Engineering Applications of Artificial Intelligence, Vol. 21, pp. 26-34, 2008.

[10] A. Holsten, T. Vetter, K. Vohland, V. Krysanova, "Impact of climate change on soil moisture dynamics in Brandenburg with a focus on nature conservation areas," Ecological Modelling, Vol. 220, pp. 2076-2087, 2009.

[11] K. Y. Li, M. T. Coe, N. Ramankutty, and R. D. Jong, "Modeling the hydrological impact of land-use change in West Africa,” Journal of Hydrology, Vol. 337, pp. 258268, 2007.

[12] J. Liu, E. Pattey, M. C. Nolin, J. R. Miller, and O. Ka, "Mapping within-field soil drainage using remote sensing,” DEM and apparent soil electrical conductivity. Geoderma, Vol. 143, pp.261-272, 2008.

[13] Y. Liu, W. Yang, and X. X. Wang, "Development of a SWAT extension module to simulate riparian wetland hydrologic processes at a watershed scale,” Hydrological Processes, Vol. 22, pp. 2901-2915, 2008.

[14] A. Loew, "Impact of surface heterogeneity on surface soil moisture retrievals from passive microwave data at the regional scale: The Upper Danube case,” Remote Sensing of Environment, Vol. 112, pp. 231-248, 2008.

[15] M. F. McCabe, E. F. Wood, R. Wójcik, M. Pan, J. Sheffield, H. Gao, and H. Su, "Hydrological consistency using multi-sensor remote sensing data for water and energy cycle studies," Remote Sensing of Environment, Vol. 112, pp. 430-444, 2008.

[16] W. N. Yang, J. Jian, Y. X. Li, X. N. Wan, L. Peng, H. H. Liu, H. Y. Shao, X. A. Dai, T. Zeng, and X. M. Wu, "Remote sensing inversion of eco-water resource quantity in international workshop on earth observation and remote sensing applications,” 29 June-2 July 2008, Beijing, China(IEEE), pp. 1-6, 2008.

[17] J. Jian, "Quantitative investigation of eco-water with remote sensing in the upper of Minjiang river,” Doctoral thesis, Chengdu University of Technology, China, 2006. 